\title{
Management of malignant hyperthermia: diagnosis and treatment
}

This article was published in the following Dove Press journal:

Therapeutics and Clinical Risk Management

14 May 2014

Number of times this article has been viewed

\section{Daniel Schneiderbanger \\ Stephan Johannsen \\ Norbert Roewer \\ Frank Schuster}

Department of Anaesthesia and Critical Care, University of Wuerzburg, Wuerzburg, Germany
Correspondence: Frank Schuster Department of Anesthesia and Critical Care, University of Wuerzburg, Oberduerrbacher Strasse 6, D-97080 Wuerzburg, Germany

$\mathrm{Tel}+4993120130038$

Fax +49 93I 20130039

Email schuster_f@ukw.de
Abstract: Malignant hyperthermia is a potentially lethal inherited disorder characterized by disturbance of calcium homeostasis in skeletal muscle. Volatile anesthetics and/or the depolarizing muscle relaxant succinylcholine may induce this hypermetabolic muscular syndrome due to uncontrolled sarcoplasmic calcium release via functionally altered calcium release receptors, resulting in hypoxemia, hypercapnia, tachycardia, muscular rigidity, acidosis, hyperkalemia, and hyperthermia in susceptible individuals. Since the clinical presentation of malignant hyperthermia is highly variable, survival of affected patients depends largely on early recognition of the symptoms characteristic of malignant hyperthermia, and immediate action on the part of the attending anesthesiologist. Clinical symptoms of malignant hyperthermia, diagnostic criteria, and current therapeutic guidelines, as well as adequate management of anesthesia in patients susceptible to malignant hyperthermia, are discussed in this review.

Keywords: malignant hyperthermia, volatile anesthetics, succinylcholine, in vitro contracture test, genetics

\section{Introduction}

Malignant hyperthermia $(\mathrm{MH})$ is a rare, but life-threatening, autosomal-dominant inherited disorder that may lead to metabolic crisis of skeletal muscle in susceptible individuals following exposure to triggering agents, such as volatile anesthetics or depolarizing muscle relaxants. ${ }^{1}$ Functionally altered calcium release channels cause dysfunction of intracellular calcium homeostasis and uncontrolled calcium release from the sarcoplasmic reticulum, which may lead rapidly to a fatal hypermetabolic state known as MH crisis. Interestingly, in everyday life, most MH-susceptible (MHS) individuals do not suffer from muscle symptoms. Nevertheless, $\mathrm{MH}$ is still a relevant complication and every anesthesiologist must recognize the symptoms of an $\mathrm{MH}$ episode and start appropriate treatment without delay.

\section{History}

From the beginning of the 20th century, there have been numerous case reports of anesthesia-associated deaths related to perioperative hyperthermia. ${ }^{2,3}$ However, it was not until 1960, when Denborough et al defined MH as an independent syndrome, that the link between deaths attributed to general anesthesia and a genetic predisposition was postulated. ${ }^{4}$ In 1975, with the introduction of dantrolene as a specific ryanodine receptor antagonist, a causative treatment became available ${ }^{5}$ and the mortality rate for acute $\mathrm{MH}$ crisis decreased from approximately $70 \%-80 \%$ to about $5 \%{ }^{6,7}$ Based on in vitro 
detection of halothane-induced and caffeine-induced contractures in skeletal muscle specimens from MHS individuals, the first diagnostic procedure was developed to distinguish between MHS and MH-non-susceptible (MHN) patients independently of a previous symptomatic $\mathrm{MH}$ event. ${ }^{8,9}$

Following these observations, a standardized protocol for in vitro contracture testing was published by the European Malignant Hyperthermia Group in 1984, and a modified protocol was introduced by the North American Malignant Hyperthermia Group 3 years later. ${ }^{10,11}$ After $\mathrm{MH}$-associated mutations in the ryanodine receptor gene were identified, guidelines for genetic testing allowing diagnosis of $\mathrm{MH}$ susceptibility in selected patients were published by the European Malignant Hyperthermia Group in 2001 and are still under development as more causative mutations become apparent. ${ }^{12}$

\section{Epidemiology}

$\mathrm{MH}$ occurs worldwide in all races. ${ }^{7}$ Children and young adults are mostly affected, with a significant male preponderance. ${ }^{7,13,14}$ According to a prevalence study in New York State between 2001 and 2005, the estimated prevalence of $\mathrm{MH}$ was 2.5-4.5 times higher in males than in females. ${ }^{15}$ Since many MHS individuals experience no symptoms in daily life, the true incidence of $\mathrm{MH}$ remains unknown. The predicted genetic prevalence is reported to be one in 2,000, while the incidence of clinical $\mathrm{MH}$ episodes varies regionally from one in 5,000 to one in 100,000. , $^{16,17}$ In contrast with fulminant episodes, abortive courses might occur more frequently, but are difficult to diagnose due to their mild symptoms. ${ }^{18}$

Recent developments in anesthesiology seem to have led to a decrease in the risk of severe $\mathrm{MH}$ crisis over the last few years. Halothane, a potent $\mathrm{MH}$-triggering agent, is no longer used in western countries. ${ }^{19}$ Compared with halothane, the onset of $\mathrm{MH}$ is delayed with the volatile anesthetics currently in use, ${ }^{20,21}$ and is more likely to be abortive $\mathrm{MH}$ with attenuated symptoms. Further, the recommended indications for succinylcholine, another possible triggering agent, have been gradually restricted by international anesthesia societies. $^{18,22}$

\section{Pathophysiology}

During excitation-contraction coupling, acetylcholine evokes an action potential at the neuromuscular endplate. This action potential is propagated to the transverse tubule, causing displacement of the charge at the dihydropyridine receptor. A conformational change at the voltage-gated dihydropyridine receptor is directly transmitted to the ryanodine receptor subtype 1 (RYR1) at the sarcoplasmic reticulum, which responds by opening. RYR1, a large ion channel, facilitates release of calcium from the sarcoplasmic reticulum into the cytosol, leading to muscle contraction by initiating cross-linking of myofilaments. Active reuptake of calcium into the sarcoplasmic reticulum via an adenosine triphosphate-dependent calcium pump terminates the muscle contraction. $^{23}$

In an $\mathrm{MH}$ crisis, the triggering agent induces prolonged opening of functionally altered ryanodine receptors, resulting in uncontrolled release of calcium from the sarcoplasmic reticulum and ongoing muscle activation presenting as rigidity. ${ }^{24-27}$ Additionally, constant activation of aerobic and anaerobic metabolism results in increased oxygen consumption, leading to hypoxia, progressive lactate acidosis, excessive production of $\mathrm{CO}_{2}$, and increased body temperature (Figure 1).

Calcium reuptake into the sarcoplasmic reticulum and sustained muscle contraction consume large amounts of adenosine triphosphate. Depletion of cellular adenosine triphosphate stores leads to protracted muscular rigidity and finally to rhabdomyolysis, when breakdown of membrane integrity results in release of the contents of cells (eg, potassium, creatine phosphokinase, myoglobin) into the circulation. $^{7,28}$

\section{Genetics}

Three mammalian isoforms of the ryanodine receptor are known: RYR1, predominant in skeletal muscle; RYR2, primarily expressed in heart muscle; and RYR3, found in the central nervous system and in skeletal and smooth muscle. ${ }^{29-31}$ From the early 1990 s, mutations in the RYR1 gene on chromosome 19q13.1 have been associated with a predisposition to $\mathrm{MH} .{ }^{32}$ More than 300 RYR1 variants have been identified to date, but only 31 mutations have been functionally tested in intracellular calcium-releasing studies and confirmed to be causative of $\mathrm{MH}$ according to the molecular genetics guidelines of the European Malignant Hyperthermia Group. ${ }^{33,34}$ Interestingly, a causative mutation in RYR1 was detected in only about $50 \%{ }^{35}$ of MHS patients. ${ }^{36-38}$ The RYR1 gene is not solely responsible for susceptibility to $\mathrm{MH}$ in all affected individuals. Another gene locus has been identified in MHS patients on chromosome 1q32, encoding the $\alpha 1$ subunit of the voltage-gated dihydropyridine receptor. ${ }^{39,40}$

\section{Agents triggering $\mathrm{MH}$}

It is well accepted that all volatile halogenated inhalational anesthetics (eg, halothane, enflurane, isoflurane, desflurane, 


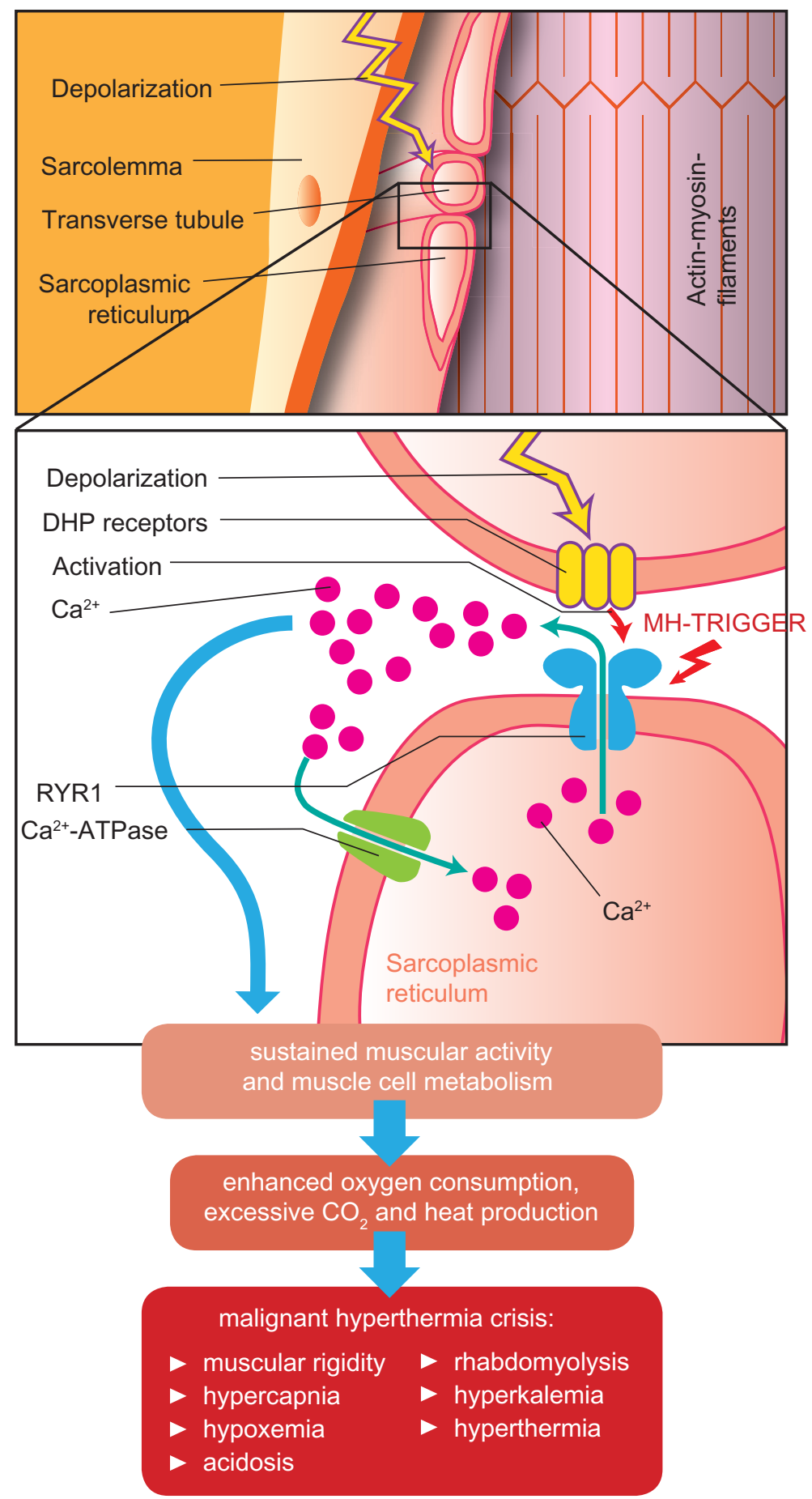

Figure I Pathophysiologic changes during a malignant hyperthermia crisis.

Abbreviations: $\mathrm{Ca}^{2+}$, calcium; DHP receptor, dihydropyridine receptor; MH, malignant hyperthermia; RYRI, ryanodine receptor subtype I.

sevoflurane) have the potential to induce an MH crisis in MHS individuals. ${ }^{41}$ Studies in MHS pigs and in vitro studies indicate that nitrous oxide and the noble gas xenon do not trigger MH. ${ }^{42-45}$ Further, it is important to mention that exposure to volatile anesthetics does not inevitably lead to $\mathrm{MH}$. Several patients have reported a number of uneventful anesthesias before an $\mathrm{MH}$ episode occurred. Triggering MH might be in part a dose-dependent phenomenon, which is consistent with the interindividual variability and graded incremental contracture response of MHS muscle during the in vitro contracture test. ${ }^{20}$ The trigger potency of the depolarizing muscle relaxant succinylcholine has been unclear for a long time, although there is no doubt that this substance enhances an $\mathrm{MH}$ reaction and decreases the likelihood of survival in 
patients who receive a combination of succinylcholine and a volatile anesthetic, compared with a volatile anesthetic alone. ${ }^{6,20}$ However, two recent retrospective studies reported a number of cases in which succinylcholine was the sole trigger of an $\mathrm{MH}$ event. ${ }^{18,46}$ Over the years, several drugs have been suspected to cause MH. However, in vitro and in vivo studies of serotonergic drugs, phosphodiesterase type III inhibitors, and ondansetron have not provided convincing evidence of their propensity to act as $\mathrm{MH}$ triggers. ${ }^{20,47}$

Interestingly, there are some reports of fulminant $\mathrm{MH}$-like episodes occurring in the absence of anesthetic agents. ${ }^{48,49} \mathrm{MH}$ episodes in the wake state have been described after excessive alcohol consumption, ${ }^{50}$ drug abuse, ${ }^{51}$ and extreme emotional and physical stress. ${ }^{52}$ A noteworthy observation which was made, was that, many patients have tested MHS on in vitro contracture testing after an exercise-induced $\mathrm{MH}$-like episode. ${ }^{53}$

\section{Clinical presentation}

Clinical symptoms of $\mathrm{MH}$ are highly variable, and range from abortive courses with mild or moderate symptoms to fulminant $\mathrm{MH}$ crises with severe skeletal muscle hypermetabolism and rhabdomyolysis. Excessive $\mathrm{CO}_{2}$ production presenting with an increase in end tidal $\mathrm{CO}_{2}$ concentration or hyperventilation while breathing spontaneously is a sensitive and specific early sign of imminent $\mathrm{MH}$. An abrupt rise in end tidal $\mathrm{CO}_{2}$ may occur simultaneously with administration of succinylcholine. ${ }^{7,54}$ Further early symptoms of an MH crisis may include tachycardia, supraventricular or ventricular arrhythmia, and isolated masseter spasm or generalized muscular rigidity. $50-80 \%$ of patients develop arrythmia or muscular reactions. ${ }^{53}$ Nonspecific sinus tachycardia might be misinterpreted as inadequate anesthesia, which often delays the diagnosis of MH. Distinctive cyanosis indicating increased oxygen consumption may occur later in the course of an $\mathrm{MH}$ episode. A rapid increase in temperature (to $>38.8^{\circ} \mathrm{C}$ ) is a relatively late sign. However, a rapid increase of $>1^{\circ} \mathrm{C}$ in 15 minutes is diagnostically more relevant than the peak temperature. ${ }^{22,55}$ In some cases, there are no relevant changes in body temperature, particularly if adequate treatment is started early. ${ }^{56,57}$ Arterial blood gas analyses reveal a combination of respiratory and metabolic acidosis with negative base excess, lactemia, hypercapnia, and hypoxemia. Fulminant $\mathrm{MH}$ crisis usually presents with $\mathrm{paCO}_{2}$ values $>60 \mathrm{mmHg}$ and a base excess of $>8 \mathrm{mVal} / \mathrm{L}$. As the MH episode progresses, rhabdomyolysis leads to hyperkalemia, increased creatine phosphokinase, and myoglobinemia, and might result in acute renal failure. The end stage of a fulminant $\mathrm{MH}$ crisis is characterized by multiorgan failure and circulatory collapse (Table 1$)^{7}$
Table I Clinical signs of malignant hyperthermia

\begin{tabular}{ll}
\hline Early & Late \\
\hline Masseter spasm & Hyperthermia \\
Generalized muscular rigidity $(50 \%-80 \%)$ & Rhabdomyolysis \\
Tachycardia $(>80 \%)$ & Acute renal failure \\
Hypercapnia & Cardiac arrhythmia \\
Hypoxia & Hypotension \\
Combined metabolic-respiratory acidosis & Circulatory failure \\
\hline
\end{tabular}

\section{Initial treatment}

The prognosis of an $\mathrm{MH}$ crisis depends on how soon $\mathrm{MH}$ is suspected and how rapidly appropriate treatment is initiated. Administration of trigger agents must be stopped immediately and anesthesia should be continued using intravenous opioids, sedatives, and, if necessary, nondepolarizing muscle relaxants. The vaporizer used for administration of volatile anesthesia should be removed from the anesthesia machine and the patient hyperventilated with $100 \%$ oxygen at maximum fresh gas flow, increasing the minute volume by approximately 2-3-fold while aiming for an end tidal $\mathrm{pCO}_{2}$ within normal limits.

Treatment includes immediate administration of dantrolene $2 \mathrm{mg} / \mathrm{kg}$, which should be repeated every 5 minutes until the cardiac and respiratory systems are stabilized. Dantrolene, a hydantoin derivative, acts as a specific ryanodine receptor antagonist and inhibits release of calcium from the sarcoplasmic reticulum without improving its reuptake. Specific side effects are rare, but include prolonged breathing problems, tissue necrosis after accidental extravasal injection, nausea, vomiting, headache, and dizziness. ${ }^{58}$

One bottle for injection contains $20 \mathrm{mg}$ of dantrolene that has to be dissolved in $60 \mathrm{~mL}$ aqua destillata. To administer $2 \mathrm{mg} / \mathrm{kg}$ to an $80 \mathrm{~kg}$ patient, $160 \mathrm{mg}$ of dantrolene (eight injection bottles) are necessary. A pharmacologic study suggested estimating the dantrolene dose needed according to the amount needed to alleviate symptoms, eg, $5 \mathrm{mg} / \mathrm{kg}$ in 24 hours if $2.5-5 \mathrm{mg} / \mathrm{kg}$ was administered initially or $10 \mathrm{mg} / \mathrm{kg}$ in 24 hours if $7.5-10 \mathrm{mg} / \mathrm{kg}$ was administered initially. If no improvement of symptoms is achieved after cumulative administration of $20 \mathrm{mg} / \mathrm{kg}$, a diagnosis of $\mathrm{MH}$ is doubtful and needs to be reconsidered (Table 2). ${ }^{57,59}$

\section{Symptomatic treatment}

Subsequent steps might be necessary to avoid further harm to the patient, and volume resuscitation and administration of vasopressors might be needed to stabilize hemodynamics. Repeated arterial blood gas analysis and monitoring of serum electrolyte, creatine phosphokinase, myoglobin, and 
Table 2 Possible differential diagnoses of acute malignant hyperthermia crisis

Differential diagnoses of malignant hyperthermia

Inadequate depth of anesthesia

Sepsis

Insufficient ventilation or spontaneous breathing

Malfunction of anesthesia machine

Anaphylactic reaction

Pheochromocytoma

Thyroid crisis

Neuromuscular disease

$\mathrm{CO}_{2}$ increase due to laparoscopic procedure

Drug intoxication

Serotonin syndrome

Malignant neuroleptic syndrome

lactate levels are important when determining the success of therapy. Administration of sodium bicarbonate or Tris buffer might be necessary to treat metabolic acidosis if $\mathrm{pH}$ is $<7.2$. Forced diuresis using fluid and furosemide can help to prevent acute renal failure. Cardiac arrhythmias are often reversible after administration of dantrolene. However, in some cases, administration of amiodarone or beta-blockers is indicated to treat persistent tachyarrhythmia. Administration of calcium antagonists is contraindicated, because severe episodes of hyperkalemia have been reported in the context of dantrolene treatment. Hyperthermia should be treated by internal cooling with cold infusion fluids and external surface cooling with ice packs placed in the axillae and groin or specific cooling devices until body temperature reaches $38.5^{\circ} \mathrm{C} .{ }^{57}$ Surgery should be terminated as soon as possible and the patient should be transferred to an intensive care unit for further monitoring and treatment (Table 3). Telephone hotlines specialized in $\mathrm{MH}$ counseling have been established in a number of countries, and a smartphone application

Table 3 Immediate causative and symptomatic treatment of acute malignant hyperthermia crisis

\begin{tabular}{ll}
\hline Causative treatment & Symptomatic treatment \\
\hline $\begin{array}{l}\text { Stop trigger agent, disconnect } \\
\text { vaporizer }\end{array}$ & $\begin{array}{l}\text { Inform surgeon, aim } \\
\text { for termination of surgery } \\
\text { as soon as possible }\end{array}$ \\
Increase respiratory minute volume & Stabilize hemodynamics \\
2-4-fold with 100\% oxygen & and start antiarrhythmic therapy \\
at maximum fresh gas flow & if appropriate \\
Administer dantrolene $2 \mathrm{mg} / \mathrm{kg}$ & Apply internal and external \\
initially & cooling \\
Continue anesthesia & Extend hemodynamic \\
with nontriggering drugs & monitoring, insert arterial line \\
& and central venous line if needed \\
Repeat dantrolene application until & Treat metabolic acidosis, \\
clinically stable (maximum $20 \mathrm{mg} / \mathrm{kg}$ ) & perform forced diuresis \\
\hline
\end{tabular}

("MHApp") issued by the European Malignant Hyperthermia Group in cooperation with the North American Malignant Hyperthermia Group can be consulted to support the initial therapeutic management. ${ }^{1}$

\section{Diagnosis of MH susceptibility}

Diagnostic testing for $\mathrm{MH}$ susceptibility can be indicated after an incident suspicious for $\mathrm{MH}$ in patients with nonspecific myopathy or persistently elevated serum creatine kinase and in families with history of $\mathrm{MH}$. For about 30 years, the in vitro contracture test using halothane and caffeine has been the gold standard for determining susceptibility to $\mathrm{MH}$ independent of a clinical $\mathrm{MH}$ event. Following a surgical muscle biopsy, live muscle specimens are exposed to defined concentrations of halothane or caffeine. If developing contracture forces exceed given thresholds after exposure to halothane and/or caffeine, the patient is diagnosed to be MHS. Absence of development of significant contracture following exposure to these agents leads to a diagnosis of MHN. There are two regional variations of this laboratory test. The in vitro contracture test according to the European Malignant Hyperthermia Group ${ }^{10}$ and the caffeine halothane contracture test according to the North American Malignant Hyperthermia Group ${ }^{11}$ differ slightly in the concentration of substance applied to the tissue bath and in mode of application (incremental versus bolus). However, adequate sensitivity and specificity has been demonstrated for both approaches. ${ }^{60,61}$ The previous existing intermediate diagnosis of MH-equivocal that was given to patients in the event of a significant reaction either after halothane or caffeine according to the European protocol has been abandoned in the recent update of the European Malignant Hyperthermia Group and replaced by the classification MHS in combination with an " $h$ " (MHSh) if contracture developed after halothane only and a "c" (MHSc) if contracture occurred after caffeine only. This measure led to further harmonization of the two protocols.

DNA analysis as an alternative to the invasive contracture test has been of increasing importance over the last decade. ${ }^{12,62}$ Only a small blood sample is required to screen for an RYR1 mutation. Molecular genetic testing is often used first line as a diagnostic tool, particularly in families with a known causative RYR1 mutation. At this time, a patient is diagnosed as MHS if one of the 31 known causative mutations is detected. However, the diagnostic classification of many RYR1 mutations remains difficult, because their pathophysiologic impact with regard to initiating an $\mathrm{MH}$ reaction is not yet clear. Therefore, an in vitro contracture 
test is required to confirm or exclude MH susceptibility in the event of an unclassified RYR1 mutation or if RYR1 mutation is absent.

A number of studies have focused on the development of less invasive functional testing procedures for determining predisposition to $\mathrm{MH}$, eg, monitoring of intramuscular lactate levels by microdialysis after locally limited trigger application in vivo ${ }^{63}$ or pharmacologic stimulation of $\mathrm{B}$ lymphocytes in vitro, given that RYR1 is also expressed on human B lymphocytes. ${ }^{60}$ Although the results have been promising, none of these methods has progressed beyond the experimental stage as yet.

In summary, in vitro contracture testing and molecular genetic testing are the two approved methods for diagnosing susceptibility to $\mathrm{MH}$. Both procedures require specialized testing centers and are not suitable for use as screening methods unless there is immediate suspicion of predisposition to $\mathrm{MH}$.

\section{Anesthesia in patients predisposed to $\mathrm{MH}$}

Providing safe anesthesia for MHS patients involves knowing about previously diagnosed $\mathrm{MH}$ status or potential susceptibility to $\mathrm{MH}$. Although patients who have undergone an in vitro contracture test or genetic testing will usually present the relevant documents without needing to be asked, specific questions about personal or family history of $\mathrm{MH}$, any critical incidents during anesthesia, and any other relevant muscular pathologies need to be asked about in every preanesthetic interview. In the event of a patient with confirmed or suspected susceptibility to $\mathrm{MH}$, it is crucial to avoid any contact with $\mathrm{MH}$ triggering substances, which include all volatile anesthetics and succinylcholine. Apart from that, no specific monitoring or treatment is required. Predisposition to $\mathrm{MH}$ alone is not a contraindication for day-case surgery. Dantrolene must be readily available at every facility where trigger substances are used. However, prophylactic administration of dantrolene is regarded as obsolete. ${ }^{49}$

Specific preparation of the anesthetic machine is required in order to prevent the MHS patient being exposed to volatile anesthetics. The necessary procedures and decontamination times vary depending on construction and applied materials among the different manufacturers and generations of machines. ${ }^{64-68}$ Maintaining a high fresh gas flow (eg, $10 \mathrm{~L}$ per minute) throughout the procedure seems to be important for avoiding a rebound phenomenon. ${ }^{64-68}$ Activated charcoal filters inserted into the breathing circuit can accelerate the purging procedure and might be valuable when preparing a machine for trigger-free anesthesia and for use in an acute MH crisis. ${ }^{69}$ Given that specific recommendations are lacking for many of the machines currently in use and that there is no clear-cut threshold for a residual concentration that is safe in terms of not triggering an $\mathrm{MH}$ crisis, an option could be to provide a specific machine within the department that has never been contaminated with volatile agents. ${ }^{70}$

\section{Conclusion}

Because of the variable clinical presentation of $\mathrm{MH}$, ranging from abortive courses with only mild or moderate symptoms to fulminate $\mathrm{MH}$ crises, patient survival depends on early recognition of symptoms of $\mathrm{MH}$ and prompt action on the part of the attending anesthesiologist. In clinics that use known $\mathrm{MH}-$ triggering agents for induction and maintenance of general anesthesia, dantrolene must be available for immediate treatment and to reduce the risk of serious harm to the patient in the event of an episode of $\mathrm{MH}$. After a suspected $\mathrm{MH}$ event, the patient should be referred to an $\mathrm{MH}$ center for further counseling.

\section{Disclosure}

The authors report no conflicts of interest in this work.

\section{References}

1. Bandschapp O, Girard T. Malignant hyperthermia. Swiss Med Wkly. 2012;142:w13652.

2. Brewer G. Heat-stroke as a post-operative complication. J Am Med Assoc. 1900;35:1685.

3. Gibson C, Tuttle J. Heat stroke as a post-operative complication. Med News (NY). 1900;77:883-884.

4. Denborough MA, Forster JF, Lovell RR, Maplestone PA, Villiers JD. Anaesthetic deaths in a family. Br J Anaesth. 1962;34:395-396.

5. Harrison GG. Control of the malignant hyperpyrexic syndrome in MHS swine by dantrolene sodium. Br J Anaesth. 1975;47:62-65.

6. Britt BA, Kalow W. Malignant hyperthermia: a statistical review. Can Anaesth Soc J. 1970;17:293-315.

7. Rosenberg H, Davis M, James D, Pollock N, Stowell K. Malignant hyperthermia. Orphanet J Rare Dis. 2007;2:21.

8. Kalow W, Britt BA, Terreau ME, Haist C. Metabolic error of muscle metabolism after recovery from malignant hyperthermia. Lancet. 1970;2:895-898.

9. Ellis FR, Harriman DG, Keaney NP, Kyei-Mensah K, Tyrrell JH. Halothane-induced muscle contracture as a cause of hyperpyrexia. $\mathrm{Br}$ J Anaesth. 1971;43:721-722.

10. [No authors listed]. A protocol for the investigation of malignant hyperpyrexia (MH) susceptibility. The European Malignant Hyperpyrexia Group. Br J Anaesth. 1984;56:1267-1269.

11. Larach MG. Standardization of the caffeine halothane muscle contracture test. North American Malignant Hyperthermia Group. Anesth Analg. 1989;69:511-515.

12. Urwyler A, Deufel T, McCarthy T, West S, European Malignant Hyperthermia Group. Guidelines for molecular genetic detection of susceptibility to malignant hyperthermia. Br J Anaesth. 2001;86:283-287.

13. Larach MG, Gronert GA, Allen GC, Brandom BW, Lehman EB. Clinical presentation, treatment, and complications of malignant hyperthermia in North America from 1987 to 2006. Anesth Analg. 2010;110: 498-507. 
14. Chamley D, Pollock NA, Stowell KM, Brown RL. Malignant hyperthermia in infancy and identification of novel RYR1 mutation. Br J Anaesth. 2000;84:500-504.

15. Brady JE, Sun LS, Rosenberg H, Li G. Prevalence of malignant hyperthermia due to anesthesia in New York State, 2001-2005. Anesth Analg. 2009; 109:1162-1166.

16. Monnier N, Krivosic-Horber R, Payen JF, et al. Presence of two different genetic traits in malignant hyperthermia families: implication for genetic analysis, diagnosis, and incidence of malignant hyperthermia susceptibility. Anesthesiology. 2002;97:1067-1074.

17. Ording H. Epidemiology of malignant hyperthermia. In: Schulte Am Esch J, Scholz J, Wappler F, editors. Malignant Hyperthermia. Lengerich, Germany: Pabst Science Publishers; 2000.

18. Schuster F, Johannsen S, Schneiderbanger D, Roewer N. Evaluation of suspected malignant hyperthermia events during anesthesia. $B M C$ Anesthesiol. 2013;13:24.

19. Bundesinstitut für Arzneimittel und Medizinprodukte. Bekanntmachung der Erlöschung fiktiver Arzneimittelzulassungen nach § 105 Abs. 3 Satz 1 des Arzneimittelgesetzes. Bundesanzeiger; 2001;11:61-62.

20. Hopkins PM. Malignant hyperthermia: pharmacology of triggering. $\mathrm{Br}$ J Anaesth. 2011;107:48-56.

21. Wedel DJ, Gammel SA, Milde JH, Iaizzo PA. Delayed onset of malignant hyperthermia induced by isoflurane and desflurane compared with halothane in susceptible swine. Anesthesiology. 1993;78:1138-1144.

22. DGAI. [Verwendung von Succinylcholin - Aktualisierte Stellungnahme der DGAI]. Anästh Intensivmed. 2002;43:831. German.

23. Melzer W, Herrmann-Frank A, Luttgau $\mathrm{HC}$. The role of $\mathrm{Ca}^{2+}$ ions in excitation-contraction coupling of skeletal muscle fibres. Biochim Biophys Acta. 1995;1241:59-116.

24. Struk A, Lehmann-Horn F, Melzer W. Voltage-dependent calcium release in human malignant hyperthermia muscle fibers. Biophys $J$. 1998;75:2402-2410.

25. Yang T, Allen PD, Pessah IN, Lopez JR. Enhanced excitation-coupled calcium entry in myotubes is associated with expression of RyR1 malignant hyperthermia mutations. J Biol Chem. 2007;282:37471-37478.

26. Mickelson JR, Gallant EM, Litterer LA, Johnson KM, Rempel WE, Louis CF. Abnormal sarcoplasmic reticulum ryanodine receptor in malignant hyperthermia. J Biol Chem. 1988;263:9310-9315.

27. Mickelson JR, Louis CF. Malignant hyperthermia: excitationcontraction coupling, $\mathrm{Ca} 2+$ release channel, and cell $\mathrm{Ca}^{2+}$ regulation defects. Physiol Rev. 1996;76:537-592.

28. Litman RS, Rosenberg H. Malignant hyperthermia: update on susceptibility testing. JAMA. 2005;293:2918-2924

29. Stathopulos PB, Seo MD, Enomoto M, Amador FJ, Ishiyama N, Ikura M. Themes and variations in ER/SR calcium release channels: structure and function. Physiology. 2012;27:331-342.

30. Fill M, Copello JA. Ryanodine receptor calcium release channels. Physiol Rev. 2002;82:893-922.

31. Hamilton SL. Ryanodine receptors. Cell Calcium. 2005;38:253-260.

32. McCarthy TV, Healy JM, Heffron JJ, et al. Localization of the malignant hyperthermia susceptibility locus to human chromosome 19q12-13.2. Nature. 1990;343:562-564.

33. European Malignant Hyperthermia Group: Causative RyR1 mutations. 2013. Available from: http://www.emhg.org/genetics/mutations-inryr1/. Accessed March 12, 2014.

34. Rosenberg H. Mining for mutations in malignant hyperthermia. Anesth Analg. 2011;113:975-976.

35. Broman M, Heinecke K, Islander G, et al. Screening of the ryanodine 1 gene for malignant hyperthermia causative mutations by high resolution melt curve analysis. Anesth Analg. 2011;113:1120-1128.

36. Robinson R, Carpenter D, Shaw MA, Halsall J, Hopkins P. Mutations in RYR1 in malignant hyperthermia and central core disease. Hum Mutat. 2006;27:977-989.

37. Sambuughin N, Holley H, Muldoon S, et al. Screening of the entire ryanodine receptor type 1 coding region for sequence variants associated with malignant hyperthermia susceptibility in the north american population. Anesthesiology. 2005;102:515-521.
38. Brandom BW. Genetics of malignant hyperthermia. ScientificWorldJournal. 2006;6:1722-1730.

39. Monnier N, Procaccio V, Stieglitz P, Lunardi J. Malignant-hyperthermia susceptibility is associated with a mutation of the alpha 1-subunit of the human dihydropyridine-sensitive L-type voltage-dependent calcium-channel receptor in skeletal muscle. Am Hum Genet. 1997;60: 1316-1325.

40. Marchant CL, Ellis FR, Halsall PJ, Hopkins PM, Robinson RL. Mutation analysis of two patients with hypokalemic periodic paralysis and suspected malignant hyperthermia. Muscle Nerve. 2004;30: 114-117.

41. Kunst G, Graf BM, Schreiner R, Martin E, Fink RH. Differential effects of sevoflurane, isoflurane, and halothane on $\mathrm{Ca}^{2+}$ release from the sarcoplasmic reticulum of skeletal muscle. Anesthesiology. 1999;91: 179-186.

42. McGrath CJ, Rempel WE, Jessen CR, Addis PB, Crimi AJ. Malignant hyperthermia-triggering liability of selected inhalant anesthetics in swine. Am J Vet Res. 1981;42:604-607.

43. Gronert GA, Milde JH. Hyperbaric nitrous oxide and malignant hyperpyrexia. Br J Anaesth. 1981;53:1238.

44. Froeba G, Marx T, Pazhur J, et al. Xenon does not trigger malignant hyperthermia in susceptible swine. Anesthesiology. 1999;91: 1047-1052.

45. Baur CP, Klingler W, Jurkat-Rott K, et al. Xenon does not induce contracture in human malignant hyperthermia muscle. Br J Anaesth. 2000;85:712-716.

46. Riazi S, Larach MG, Hu C, Wijeysundera D, Massey C, Kraeva N. Malignant hyperthermia in Canada: characteristics of index anesthetics in 129 malignant hyperthermia susceptible probands. Anesth Analg. 2014;118:381-387.

47. Johannsen S, Roewer N, Schuster F. Ondansetron-induced muscular contractures in malignant hyperthermia-susceptible individuals. Anesth Analg. 2012;115:925-928.

48. Capacchione JF, Muldoon SM. The relationship between exertional heat illness, exertional rhabdomyolysis, and malignant hyperthermia. Anesth Analg. 2009;109:1065-1069.

49. Wappler F. Anesthesia for patients with a history of malignant hyperthermia. Curr Opin Anaesthesiol. 2010;23:417-422.

50. Loghmanee F, Tobak M. Fatal malignant hyperthermia associated with recreational cocaine and ethanol abuse. Am J Forensic Med Pathol. 1986;7:246-248

51. Merigian KS, Roberts JR. Cocaine intoxication: hyperpyrexia, rhabdomyolysis and acute renal failure. J Toxicol Clin Toxicol. 1987;25: 135-148.

52. Wappler F, Fiege M, Steinfath M, et al. Evidence for susceptibility to malignant hyperthermia in patients with exercise-induced rhabdomyolysis. Anesthesiology. 2001;94:95-100.

53. Wappler F. Malignant hyperthermia. Eur J Anaesthesiol. 2001;18: 632-652.

54. Tautz TJ, Urwyler A, Antognini JF, Riou B. Case scenario: increased end-tidal carbon dioxide: a diagnostic dilemma. Anesthesiology. 2010;112:440-446.

55. Larach MG, Localio AR, Allen GC, et al. A clinical grading scale to predict malignant hyperthermia susceptibility. Anesthesiology. 1994;80:771-779.

56. Ali SZ, Taguchi A, Rosenberg H. Malignant hyperthermia. Best Pract Res Clin Anaesthesiol. 2003;17:519-533.

57. Glahn KP, Ellis FR, Halsall PJ, et al. Recognizing and managing a malignant hyperthermia crisis: guidelines from the European Malignant Hyperthermia Group. Br J Anaesth. 2010;105:417-420.

58. Schuster F, Muller-Reible CR. [Malignant hyperthermia-diagnostics, treatment and anaesthetic management]. Anasthesiol Intensivmed Notfallmed Schmerzther. 2009;44:758-763. German.

59. Podranski T, Bouillon T, Schumacher PM, Taguchi A, Sessler DI, Kurz A. Compartmental pharmacokinetics of dantrolene in adults: do malignant hyperthermia association dosing guidelines work? Anesth Analg. 2005;101:1695-1699. 
60. Sei Y, Brandom BW, Bina S, et al. Patients with malignant hyperthermia demonstrate an altered calcium control mechanism in B lymphocytes. Anesthesiology. 2002;97:1052-1058.

61. Allen GC, Larach MG, Kunselman AR. The sensitivity and specificity of the caffeine-halothane contracture test: a report from the North American Malignant Hyperthermia Registry. The North American Malignant Hyperthermia Registry of MHAUS. Anesthesiology. 1998;88:579-588.

62. Gunter C. Quantitative genetics. Nature. 2008;456:719.

63. Schuster F, Metterlein T, Negele S, et al. An in-vivo metabolic test for detecting malignant hyperthermia susceptibility in humans: a pilot study. Anesth Analg. 2008;107:909-914.

64. Kim TW, Nemergut ME. Preparation of modern anesthesia workstations for malignant hyperthermia-susceptible patients: a review of past and present practice. Anesthesiology. 2011;114:205-212.

65. Prinzhausen H, Crawford MW, O'Rourke J, Petroz GC. Preparation of the Drager Primus anesthetic machine for malignant hyperthermiasusceptible patients. Can J Anaesth. 2006;53:885-890.
66. Crawford MW, Prinzhausen H, Petroz GC. Accelerating the washout of inhalational anesthetics from the Drager Primus anesthetic workstation: effect of exchangeable internal components. Anesthesiology. 2007; 106:289-294.

67. Shanahan H, O’Donoghue R, O'Kelly P, Synnott A, O'Rourke J. Preparation of the Drager Fabius CE and Drager Zeus anaesthetic machines for patients susceptible to malignant hyperthermia. Eur $J$ Anaesthesiol. 2012;29:229-234.

68. Kim TW, Tham RQ. Washout times of desflurane, sevoflurane and isoflurane from the GE healthcare Aisys ${ }^{\mathbb{B}}$ and Avance ${ }^{\mathbb{B}}$ Carestation $^{\circledR}$ and Aestiva $^{\mathbb{R}}$ anesthesia system. Paediatr Anaesth. 2013;23:1124-1130.

69. Birgenheier N, Stoker R, Westenskow D, Orr J. Activated charcoal effectively removes inhaled anesthetics from modern anesthesia machines. Anesth Analg. 2011;112:1363-1370.

70. Martin JW, Welliver MD. Activated charcoal adsorption of volatile anesthetic agents for anesthesia machine preparation of malignant hyperthermia susceptible patients. AANA J. 2013;81:169-171.
Therapeutics and Clinical Risk Management

\section{Publish your work in this journal}

Therapeutics and Clinical Risk Management is an international, peerreviewed journal of clinical therapeutics and risk management, focusing on concise rapid reporting of clinical studies in all therapeutic areas, outcomes, safety, and programs for the effective, safe, and sustained use of medicines. This journal is indexed on PubMed Central, CAS,

\section{Dovepress}

EMBase, Scopus and the Elsevier Bibliographic databases. The manuscript management system is completely online and includes a very quick and fair peer-review system, which is all easy to use. Visit http://www.dovepress.com/testimonials.php to read real quotes from published authors.

Submit your manuscript here: http://www.dovepress.com/therapeutics-and-clinical-risk-management-journal 